\title{
Application of spontaneously closing cannula ileostomy in laparoscopic anterior resection of rectal cancer
}

\author{
DONG CHEN $^{1 *}$, HUIYING ZHAO ${ }^{1 *}$, QIANG HUANG ${ }^{2}$, XIANGMING XU $^{1}$, XIAOFEI CHENG ${ }^{1}$, \\ BINGXIN KE ${ }^{1}$, DANYANG WANG ${ }^{1}$, HANJU HUA ${ }^{1}$, JIAHE XU ${ }^{1}$, JIANJIANG LIN ${ }^{1}$ and FENG YE ${ }^{1}$ \\ Departments of ${ }^{1}$ Colorectal Surgery and ${ }^{2}$ Radiology, First Affiliated Hospital, College of Medicine, \\ Zhejiang University, Hangzhou, Zhejiang 310003, P.R. China
}

Received August 3, 2016; Accepted August 22, 2017

DOI: $10.3892 / \mathrm{ol} .2017 .6872$

\begin{abstract}
An anastomotic leak (AL) is the most serious complication observed in laparoscopic anterior resection of rectal cancer (LARRC). In order to protect anastomosis from AL and avoid stoma reversal surgery in patients with ileostomy, spontaneously closing cannula ileostomy (SCCI) was used in LARRC and its safety and feasibility were assessed in the present study. To the best of our knowledge, this is the first time that SCCI has been used in such a case. A total of 41 patients who underwent LARRC with SCCI or ileostomy procedures between November 2013 and August 2014 were retrospectively analyzed. The patient demographics, clinical features and surgical data were evaluated using a Mann-Whitney U-test, Fisher's exact test or linear-by-linear association. Demographics, surgical data and the majority of clinical features of the two groups were consistently similar. In the SCCI group, the length of postoperative stay, total cost and stoma period were significantly improved compared with those in the ileostomy group. Additionally, the median protective period in the SCCI group was 22 days [interquartile range (IQR), 19-22 days], the median time to cannula removal was 23 days (IQR, 20-24 days) and the median time to cannula stoma closure was 12 days (IQR, 11-13 days). No SCCI-associated complications occurred. No significant differences in routine
\end{abstract}

Correspondence to: Professor Feng Ye, Department of Colorectal Surgery, First Affiliated Hospital, College of Medicine, Zhejiang University, 79 Qingchun Road, Hangzhou, Zhejiang 310003, P.R. China

E-mail: yefengcnzjhz@hotmail.com

*Contributed equally

Abbreviations: AL, anastomotic leak; ASA, American Society of Anesthesiologists; BMI, body mass index; LARRC, laparoscopic anterior resection of rectal cancer; SCCI, spontaneously closing cannula ileostomy; TME, total mesorectal excision; VIB, Valtrac $^{\mathrm{TM}}$-secured intracolonic bypass

Key words: anastomotic leak, anterior resection, ileostomy, spontaneously closing cannula ileostomy, rectal cancer complications, including staple-line bleeding, anastomotic leak, anastomotic dehiscence, anastomotic stenosis and wound infection, were identified between the two groups. In LARRC, the SCCI procedure was demonstrated to be a safe and feasible diverting technique to protect anastomosis from AL. In contrast to ileostomy, the SCCI procedure obviated the requirement for stoma reversal surgery, which resulted in decreased lengths of postoperative hospital stay, hospitalization costs and stoma periods.

\section{Introduction}

Throughout the evolution of rectal cancer resection, an anastomotic leak (AL) has been considered the most serious postoperative complication. Although laparoscopic anterior resection of rectal cancer (LARRC) and intracorporeal anastomosis possess several technical drawbacks, including the lack of direct tactile sense, inadequate traction and an ineffective cutting angle of the end linear surgical stapler (1), the rate of AL in LARRC is similar to that of open surgery; reported to be between 6 and 17\% (2-9). Furthermore, previous studies have demonstrated that LARRC is safe and feasible (10-14).

AL often results in serious outcomes, including sepsis and emergency surgery, with ensuing prolonged hospital stays, increased costs, and increased morbidity and mortality $(15,16)$. Previously, ileostomy was the only widely used method of avoiding AL-associated complications $(17,18)$ despite the possibility of stoma-associated complications and a secondary surgery to close the stoma, which increase patient distress, overall costs and results in additional scarring $(19,20)$.

To protect the anastomosis and avoid stoma reversal surgery two novel surgical methods, the Valtrac ${ }^{\mathrm{TM}}$-secured intracolonic bypass (VIB) and the spontaneously closing cannula ileostomy (SCCI), were developed in the Department of Colorectal Surgery at The First Affiliated Hospital, Zhejiang University (Hangzhou, Zhejiang, China). The use of VIB has been reported in open surgery $(21,22)$ and laparoscopic surgery (23), whereas the use of SCCI has been reported in open procedures and hand-assisted laparoscopic surgery (24-26). Suturing of the ileum to the peritoneum could not be finished under laparoscopic guidance, therefore, SCCI was not performed during laparoscopic surgery until 
the location of the SCCI was moved in November 2013. Subsequently, the SCCI technique was applied to LARRC. The present study assessed the efficacy and safety of SCCI in LARRC in comparison with ileostomy.

\section{Patients and methods}

Patients. The medical records of 41 consecutive patients with rectal cancer who had undergone selective LARRC with SCCI or ileostomy procedures to protect the anastomosis in the Department of Colorectal Surgery, First Affiliated Hospital, Zhejiang University, between November 2013 and August 2014, were retrospectively reviewed. All patients were followed up for $\geq 6$ months following laparoscopic surgery. Patients in the ileostomy group were followed up for at least 3 months after reversal surgery.

Approval for the study was obtained from the Institutional Review Board of the First Affiliated Hospital, College of Medicine, Zhejiang University. Although a number of patients did not receive protective procedures in later surgery, all patients were informed about the LARRC, ileostomy or SCCI procedures preoperatively. Written consent was obtained from the patients between 1 and 3 days prior to the surgery. Inclusion criteria for the laparoscopic surgery were: i) A localized tumor $>4$ and $<12 \mathrm{~cm}$ from the anal verge; ii) compliance with laparoscopy procedures; and iii) sufficient heart and lung function to withstand laparoscopic surgery. Exclusion criteria for the minimally invasive approach were: i) Cancer infiltrating contiguous organs [T4 of the Tumor-Node-Metastasis (TNM) colorectal cancer staging system] (27); ii) counter-indications to the pneumoperitoneum; and iii) a long-axis tumor size $>6 \mathrm{~cm}$. Preoperative study was based on locoregional staging using transanal ultrasonography or magnetic resonance imaging scans, and contrast-enhanced computed tomography scans of the thorax, abdomen and pelvis.

Patients with locally advanced rectal carcinomas (T3N0 or $\mathrm{N}+$ of the TNM colorectal cancer staging system) were routinely suggested to receive neoadjuvant chemoradiation of 25 fractions of 45 Gy over 5 weeks, with $825 \mathrm{mg} / \mathrm{m}^{2}$ oral capecitabine twice daily (28). However, these suggestions were rejected by a number of the patients or their relatives. All patients treated with preoperative chemoradiation underwent surgery within 6 to 8 weeks of completing neoadjuvant therapy. Appropriate demographic information comprised age, sex, American Society of Anesthesiologists (ASA) score, body mass index (BMI), comorbidities, smoking status, level of tumor (the distance from the inferior margin of tumor to the anus) and neoadjuvant therapies. Measured outcomes included: Level of anastomosis, surgical duration, intraoperative blood loss, number of linear stapler firings, postoperative complications, length of postoperative stay, cost for LARRC, total cost (which included the cost of reversal surgery in the ileostomy group), Duke's stage, number of harvested lymph nodes and return of bowel function. Additionally, the protective period, the time to cannula removal and the time to cannula stoma closure were assessed in the SCCI group. Wounds were monitored daily until patients were discharged, and a follow-up of between 1 and 2 weeks was performed to observe any signs of infection.

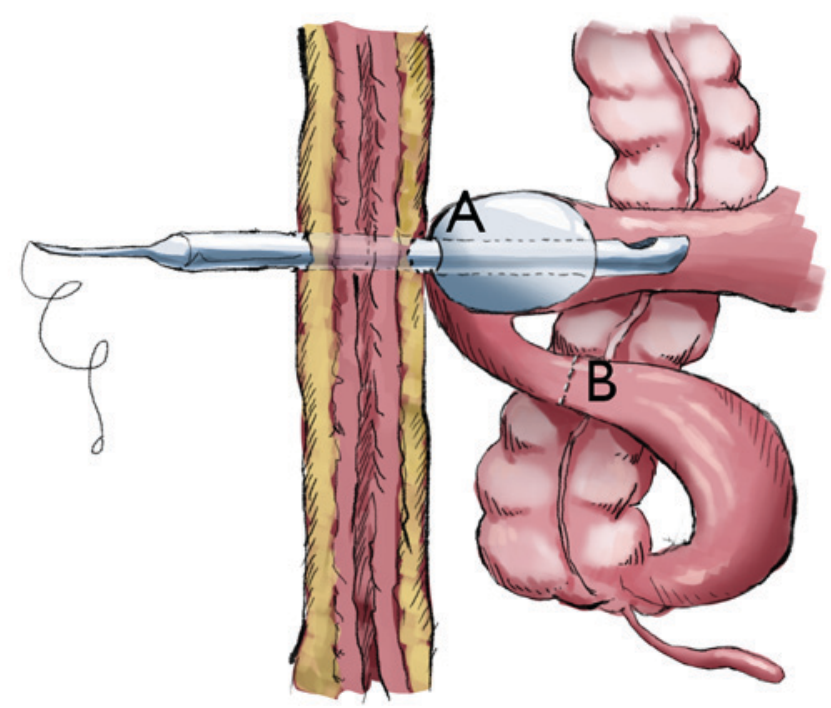

Figure 1. Schematic diagram of the SCCI technique. (A) The location of SCCI. (B) Distal bowel blocked by one-row nail stapling. SCCI, spontaneously closing cannula ileostomy.

\section{Surgery}

Surgical technique for laparoscopic anterior resection. The patients were placed in a modified lithotomy, right side down, in the Trendelenburg position. The open technique was used to introduce an initial $10-\mathrm{mm}$ port, inferior to the umbilicus, prior to formation of a pneumoperitoneum using carbon dioxide. The gas line was connected and the laparoscope introduced. Subsequently, two $5-\mathrm{mm}$ ports were inserted in the upper right and left abdominal quadrants, and one $12-\mathrm{mm}$ port was inserted in the lower right abdominal quadrant under laparoscopic guidance. For the very low anastomosis patients, an additional 5-mm port was inserted between 3 and $4 \mathrm{~cm}$ superior to the upper margin of the pubic symphysis.

The procedure permitted the laparoscopic no-touch isolation technique, the so-called 'medial to lateral' approach and total mesorectal excision (TME) principles. Following mobilization of the left colon, if necessary, mobilization of the splenic flexure was performed; intracorporeal ligation of the inferior mesenteric vessels was performed, followed by mobilization of the rectum and the mesorectum. The peritoneum was cut from the lateral side to complete full mobilization prior to intracorporeal transection of the distal bowel, using a 45- or 60-mm Endo GIA stapler (Ethicon, Inc.; Johnson \& Johnson, Cincinnati, OH, USA). The bowel was extracted through a small incision made beneath a wound protector in the left lower quadrant port and subsequently removed from associated proximal bowel. Purse string sutures were applied at the proximal stumps using straight needles (3-0 Maxon ${ }^{\mathrm{TM}}$, United States Surgical, Norwalk, CT, USA) and monofilament absorbable thread. A pocket was created locally to the proximal end of the sigmoid colon, and the anvil of an end-to-end anastomotic stapler (Ethicon Inc, Johnson \& Johnson, Miami, FL, USA) was inserted and fixed. The stapler was inserted through the anus into the pelvic cavity. Following stapling, the anastomotic site and stapler were evaluated, and any anastomotic tears were sutured. Subsequently, SCCI or ileostomy was performed. 

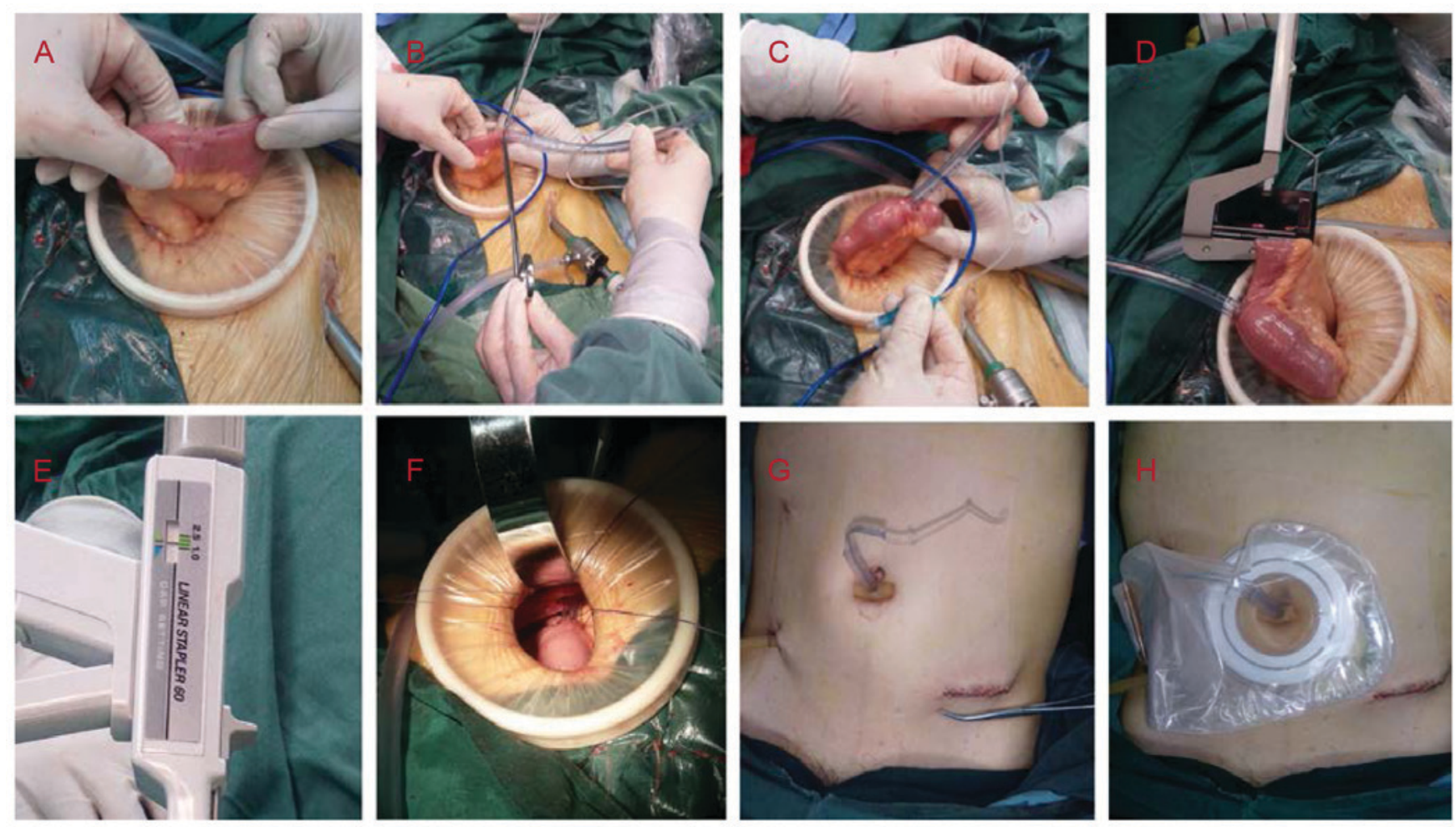

Figure 2. Images captured during the spontaneously closing cannula ileostomy technique. (A) A purse string was made in the distal ileum $20-28 \mathrm{~cm}$ from the ileocecal valve. (B) A 7.5-mm diameter tracheal tube was inserted into the bowel directed toward the proximal lumen. (C) The gas bag at the head of the tube was filled with 7-10 $\mathrm{ml}$ normal saline. (D) The small bowel was blocked at 5-8 $\mathrm{cm}$ from the purse string and 15-20 cm from the ileocecal valve, using a TL60 stapler. (E) The appropriate closing thickness was $1.5-2.0 \mathrm{~mm}$. (F) The bowel wall close to the tube was sewn onto the peritoneum using 2-3 monofilament absorbable threads. (G) A short flexible rubber tube was set around the tube outside the abdominal skin to fix the tracheal tube. (H) An ostomy bag was placed to collect intestinal contents.

SCCI technique. Previously, two SCCI techniques have been reported by the Department of Colorectal Surgery, First Affiliated Hospital, Zhejiang University $(24,26)$. An appropriate diversion of the distal small bowel was performed in the two methods to provide temporary diversion; the distinction was whether a stapler was used to block the distal ileum or not. In the present study, the SCCI protocol followed the method of $\mathrm{Xu}$ et al (26) (Fig. 1).

First, a purse string (3-0 Vicryl ${ }^{\mathrm{TM}}$; Johnson \& Johnson, New Brunswick, NJ, USA) was made in the distal ileum $20-28 \mathrm{~cm}$ from the ileocecal valve (Fig. 2A). The diameters of the purse-string rings were $\sim 10 \mathrm{~mm}$. Thereafter, a small incision was created within the purse string; a $7.5-\mathrm{mm}$ diameter hard trachea cannula (QC-01; Hangzhou Jinlin Medical Appliances Co., Ltd., Hangzhou, China) was then inserted, directed toward the proximal lumen (Fig. 2B). Normal saline $(7-10 \mathrm{ml})$ was then injected into the air bag of the cannula until the ileum wall began to turn pale (Fig. 2C). The quantity of liquid was dependent on the inner diameter of the ileum cavity. The filled air bag prevented the cannula from slipping off of the ileum and also prevented downward intestinal content travel to a certain degree.

Second, the small bowel was blocked at B position (presented in Fig. 1) $5-8 \mathrm{~cm}$ from the purse string and $15-20 \mathrm{~cm}$ from the ileocecal valve, using a TL60 stapler (Ethicon Inc.; Johnson \& Johnson; Fig. 2D). One row of nails, instead of the original two rows, was applied, with an appropriate closing thickness of between 1.5 and $2.0 \mathrm{~mm}$ (Fig. 2E).
Third, the cannula was pulled out of the abdominal cavity through the initial $10-\mathrm{mm}$ port inferior to the umbilicus. The seromuscular layer of the ileum was sutured to the same location in the peritoneum, close to the tube; and the interrupted cyclic fixation was completed using 3 or 4 absorbable sutures (3-0 Vicryl; Johnson \& Johnson; Fig. 2F). The tube was then pulled tight and the sutures at the fixation site were tightly knotted. The suturing process is important to avoid abdominal infection following tube extraction and it aintains the adhesion of bowel and peritoneum close to the tube. Finally, a short flexible rubber tube was set around the tube outside the abdominal skin to fix the tracheal tube (Fig. 2G), and then an ostomy bag was placed to collect intestinal contents (Fig. 2H).

Ileostomy technique. The technical aspects of ileostomy have been well studied (24). The stomas were placed on the lower right side of the abdomen and were closed between 3 and 6 months later.

\section{Assessment and definition}

Bowel function. Return of bowel function was defined as the first passage of flatus or bowel movement with tolerance of an oral diet. Ileus was defined as a delayed return of bowel function. Observed symptoms of ileus included abdominal distention, intolerance of an oral diet, nausea or radiographic evidence of dilated bowel with no evident obstruction. Bowel obstruction was defined as exhibiting similar symptoms to ileus with the distinction that these symptoms were accompanied 
by radiographic evidence of the dilated bowel with a clear obstruction observed. In the SCCI group, once bowel function recovered, the patients were provided a liquid diet or a no-residue semiliquid diet until the cannula was removed. The special diet supplement was administered in order to prevent obstruction of the minor-caliber cannula stoma.

$A L$, dehiscence and stenosis. Routine examination of the anastomosis was performed at $\sim 7$ and 14 days postoperatively by digital rectal examination. If necessary, a Urografin enema colonography was performed to assess the anastomosis. Digital rectal examination and colonography were conducted on all patients in the ileostomy group prior to the reversal surgery in order to avoid AL, dehiscence and stenosis (Fig. 3).

AL was defined as a defect in intestinal wall integrity at the colorectal or coloanal anastomosis site, leading to communication between the intra- and extra-luminal compartments, and may be diagnosed through digital rectal examination or colonography. Anastomotic dehiscence was defined as incomplete anastomosis, usually detected through digital rectal examination and lacking clinical manifestations. Anastomotic stenosis was detected upon digital rectal examination or colonography, and an additional procedure to relieve the stenosis was inevitably required prior to undertaking the reversal surgery.

Time to cannula removal and cannula stoma closure. Time to cannula removal was defined as the duration from laparoscopic surgery to cannula removal. The criteria for removing cannula were: i) A period of at least 14 days postoperatively; ii) recovered anal defecation; and iii) absence of evident dehiscence on digital examination, and colonography if required. When AL occurred, if an emergency surgery was not required, the cannula was retained and the patient received total parenteral nutrition or enteral nutrition until the AL was closed. Time to cannula stoma closure was defined as the duration from cannula removal to the closure of cannula stoma. This time impacted patient quality of life.

Protective period and stoma period. The stoma period in the SCCI group was defined as the period from the surgery to the closure of cannula stoma, which included the time to cannula removal and the time to cannula stoma closure, as aforementioned. The stoma period in the ileostomy group refers to the duration between the laparoscopic surgery and the reversal surgery. This time impacted the patient quality of life.

Statistical analysis. Due to the small sample size of the two treatment groups, continuous and ordinal data were presented as median with interquartile range (IQR; range between the 25 and 75 th percentiles). Comparisons of non-parametric data between groups were performed using the Mann-Whitney $\mathrm{U}$ test. The categorical data were presented as numbers and percentages, and Fisher's exact test was performed for comparisons between groups. The categorical data of Dukes' stage was evaluated using linear-by-linear association. A two-tailed P-value of $<0.05$ was considered to indicate a statistically significant difference. All statistical analyses were performed using SPSS (version 16.0; SPSS, Inc., Chicago, IL, USA).
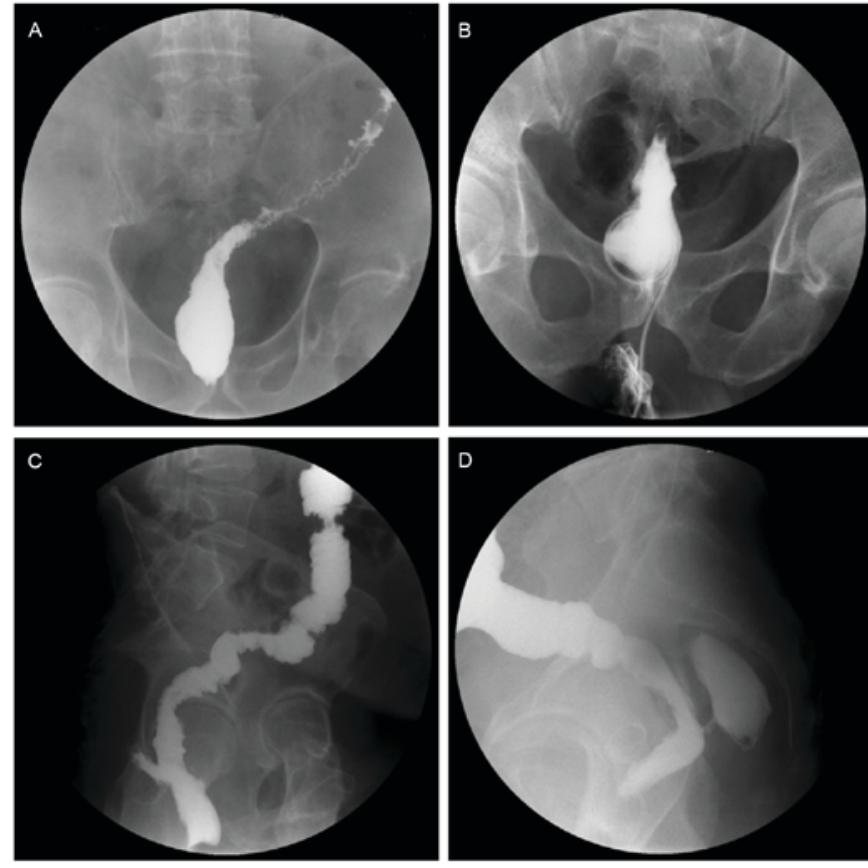

Figure 3. Colonography for assessing anastomosis (X-ray film image): (A) Normal anastomosis, (B) anastomotic stenosis (posteroanterior view), (C) anastomotic leak (oblique view) and (D) anastomotic leak (lateral view).

\section{Results}

Between November 2013 and August 2014 the SCCI and ileostomy techniques were performed in 19 and 22 cases of LARRC, respectively. The demographic data and preoperative symptoms of the patients were similar in the two groups, including age, sex, ASA score, BMI, smoking status, preexisting diseases, level of tumor (the distance from the inferior margin of tumor to the anus) and neoadjuvant radio-chemotherapy (Table I).

The intraoperative and postoperative patient data are presented in Table II. No significant differences in the level of anastomosis, surgical time, intraoperative blood loss, number of linear stapler firings, adverse events, cost of LARRC, distribution of Duke's stage, number of harvested lymph nodes or time of bowel function recovery were identified ( $\mathrm{P}>0.05)$. Due to the inevitability of reversal surgery in the ileostomy group, the overall postoperative hospital stay was significantly increased compared with that in the SCCI group (median, 13 vs. 7 days; $\mathrm{P}<0.001$ ); the total cost in the ileostomy group was also significantly increased compared with that in the SCCI group (median, $\$ 11,350$ vs. $\$ 6,500 ; \mathrm{P}<0.001$ ).

AL occurred in 1 case in the SCCI group, at day 6 postoperatively, in a patient exhibiting a fever $\left(38.5-38.8^{\circ} \mathrm{C}\right.$ for 2 days and $37.8-38.2^{\circ} \mathrm{C}$ for 3 days) and drainage of muddy liquid (10-20 ml, duration of 6 days). There was no serious sepsis or emergency surgery required in this patient, which was a benefit of the protection afforded by SCCI. For patients in the protective period, feces had not passed through the anastomosis. A total of 2 patients with stapled anastomotic stenosis were identified in the ileostomy group where an additional procedure to relieve the stenosis was subsequently performed.

With the key aim of avoiding emergency surgery as a result of AL, in the SCCI group the median protective period was 
Table I. General patient characteristics.

\begin{tabular}{|c|c|c|c|c|}
\hline Characteristic & All patients $(n=41)$ & SCCI patients $(n=19)$ & Ileostomy patients $(n=22)$ & P-value \\
\hline Age $^{\mathrm{a}}$, years & $64(61-67.5)$ & $64(59-68)$ & $64.5(62-67.8)$ & 0.409 \\
\hline $\operatorname{Sex}^{\mathrm{b}}$ & & & & $>0.999$ \\
\hline Female & $17(41.5)$ & $8(42.1)$ & $9(40.9)$ & \\
\hline Male & $24(58.5)$ & $11(57.9)$ & $13(59.1)$ & \\
\hline ASA score ${ }^{a}$ & $1(1-1)$ & $1(1-1)$ & $1(1-1)$ & 0.286 \\
\hline $\mathrm{BMI}^{\mathrm{a}}, \mathrm{kg} / \mathrm{m}^{2}$ & $23.6(22.9-24.1)$ & $23.5(22.5-24.1)$ & $23.6(23.1-24.5)$ & 0.505 \\
\hline Diabetes $^{\mathrm{b}}$ & $8(19.5)$ & $4(21.1)$ & $4(18.2)$ & $>0.999$ \\
\hline Hypertension $^{\mathrm{b}}$ & $11(26.8)$ & $5(26.3)$ & $6(27.3)$ & $>0.999$ \\
\hline Smoker ${ }^{\mathrm{b}}$ & $10(24.4)$ & $5(26.3)$ & $5(22.7)$ & $>0.999$ \\
\hline Level of tumor ${ }^{\mathrm{a}}, \mathrm{cm}$ & $7(6-8)$ & $7(6-8)$ & $7(5-8)$ & 0.698 \\
\hline Neoadjuvant radio-chemotherapy ${ }^{\mathrm{b}}$ & $6(14.6)$ & $3(15.8)$ & $3(13.6)$ & $>0.999$ \\
\hline
\end{tabular}

${ }^{a}$ Data are presented as median (inter-quartile range) and tested using the Mann-Whitney U test. ${ }^{b}$ Data are presented as number of patients (percentage) and tested using Fisher's exact test. ASA, American Society of Anesthesiologists; BMI, body mass index; SCCI, spontaneously closing cannula ileostomy.

Table II. Surgical patient data.

\begin{tabular}{|c|c|c|c|c|}
\hline Characteristic & All patients $(n=41)$ & SCCI patients $(\mathrm{n}=19)$ & Ileostomy patents $(\mathrm{n}=22)$ & P-value \\
\hline Level of anastomosis ${ }^{\mathrm{a}}, \mathrm{cm}$ & $4(3-5)$ & $4(3-5)$ & $4(3-5)$ & 0.559 \\
\hline Surgical time ${ }^{\mathrm{a}}$, min & $200(177.5-214.5)$ & $199(175-214)$ & $201(177-223)$ & 0.763 \\
\hline Intraoperative blood loss ${ }^{\mathrm{a}}$ & $100(50-100)$ & $50(50-100)$ & $100(50-100)$ & 0.277 \\
\hline Number of linear stapler firings ${ }^{\mathrm{a}}$ & $3(3-3)$ & $3(2-3)$ & $3(3-4)$ & 0.077 \\
\hline \multicolumn{5}{|l|}{ Adverse events } \\
\hline Staple-line bleeding ${ }^{\mathrm{b}}$ & $3(7.3)$ & $1(5.3)$ & $2(9.1)$ & $>0.999$ \\
\hline Anastomotic leak ${ }^{\mathrm{b}}$ & $1(2.4)$ & $1(5.3)$ & $0(0.0)$ & 0.463 \\
\hline Anastomotic dehiscence ${ }^{b}$ & $3(7.3)$ & $1(5.3)$ & $2(9.1)$ & $>0.999$ \\
\hline Wound infection ${ }^{\mathrm{b}, \mathrm{c}}$ & $5(12.2)$ & $2(10.5)$ & $3(13.6)$ & $>0.999$ \\
\hline Stapled anastomotic stenosis ${ }^{\mathrm{b}}$ & $2(4.9)$ & $0(0.0)$ & $2(9.1)$ & 0.490 \\
\hline Length of post-operative stay, days ${ }^{\mathrm{a}, \mathrm{b}, \mathrm{d}}$ & $12(7-13.5)$ & $7(7-9)$ & $13(13-15.25)$ & $<0.001$ \\
\hline \multicolumn{5}{|l|}{ Cost in $\$ 1,000$ s } \\
\hline Cost for LARRC ${ }^{a}$ & $6.6(6.4-6.75)$ & $6.5(6.4-6.7)$ & $6.6(6.4-6.825)$ & 0.502 \\
\hline Total $\operatorname{cost}^{\mathrm{a}, \mathrm{c}, \mathrm{d}}$ & $10.9(6.55-11.4)$ & $6.5(6.4-6.7)$ & $11.35(11.1-11.6)$ & $<0.001$ \\
\hline \multicolumn{5}{|l|}{ Duke's stages $^{\mathrm{e}}$} \\
\hline $\mathrm{A}\left(\mathrm{T}_{1-2} \mathrm{~N}_{0} \mathrm{M}_{0}\right)$ & $4(9.8)$ & $2(10.5)$ & $2(9.1)$ & 0.814 \\
\hline $\mathrm{B}\left(\mathrm{T}_{3-4} \mathrm{~N}_{0} \mathrm{M}_{0}\right)$ & $30(73.2)$ & $14(73.7)$ & $16(72.7)$ & \\
\hline $\mathrm{C}\left(\mathrm{T}_{\mathrm{X}} \mathrm{N}_{1-2} \mathrm{M}_{0}\right)$ & $7(17.1)$ & $3(15.8)$ & $4(18.2)$ & \\
\hline Number of harvested lymph nodes ${ }^{\mathrm{a}}$ & $13(12-14.5)$ & $14(12,15)$ & $13(12-13.25)$ & 0.100 \\
\hline \multicolumn{5}{|l|}{ Time of bowel function recovery, days } \\
\hline First flatus postoperatively ${ }^{\mathrm{a}}$ & $3(3-3)$ & $3(3-3)$ & $3(3-4)$ & 0.162 \\
\hline Oral intake $\mathrm{a}^{\mathrm{a}}$ & $3(3-4)$ & $3(3-4)$ & $3(3-4)$ & 0.541 \\
\hline
\end{tabular}

${ }^{a}$ Data are presented as median (inter-quartile range) and tested by Mann-Whitney U test. ${ }^{b}$ Data are presented as number of patients (percentage) and tested by Fisher's exact test. ${ }^{\circ}$ The ileostomy group includes the patients readmitted for reversal surgery. ${ }^{\mathrm{d}} \mathrm{P}<0.05$ indicates a statistically significant difference between the 2 groups. ${ }^{e}$ Data are presented as number of patients (percentage) and tested by linear by linear association test. SCCI, spontaneously closing cannula ileostomy; LARRC, laparoscopic anterior resection of rectal cancer.

22 days (IQR, 19-22 days). The median time to cannula removal and cannula stoma closure were 23 days (IQR, 20-24 days) and
12 days (IQR, 11-13 days), respectively. The stoma period in the SCCI group was significantly decreased compared with 
Table III. Protective period, time to cannula removal, time to cannula stoma closure and stoma period.

\begin{tabular}{|c|c|c|c|c|}
\hline Parameter, days & All patients $(n=41)$ & SCCI patients $(\mathrm{n}=19)$ & Ileostomy patients $(\mathrm{n}=22)$ & P-value \\
\hline Protective period & & $22(19-22)$ & & \\
\hline Time to cannula removal & & $23(20-24)$ & & \\
\hline Time to cannula stoma closure & & $12(11-13)$ & & \\
\hline Stoma period $^{\mathrm{a}}$ & $89(34-95)$ & $34(31-37)$ & $95(91-99)$ & $<0.001$ \\
\hline
\end{tabular}

${ }^{\mathrm{a}} \mathrm{P}<0.05$ analyzed using the Mann-Whitney U test. Data are presented as the median (interquartile range). SCCI, spontaneously closing cannula ileostomy.

that in the ileostomy group (median, 34 vs. 95 days; $\mathrm{P}<0.001$ ), which led to improved patient quality of life (Table III).

\section{Discussion}

AL remains the most serious early postoperative complication following rectal cancer resection using open and laparoscopic techniques (2-5,7-9,29-32), frequently exhibiting early adverse effects on bowel function and quality of life (33). Furthermore, numerous studies suggested that the increased incidence of negative prognostic factors, including local recurrence, functional disorders and mortality, were associated with AL (2,15,16,34-38). Despite much effort, even the most experienced surgeon is unable to avoid AL in all cases. The major risk factors for AL include being male, older age, smoking, obesity, TME, blood loss, neoadjuvant radiotherapy, corticosteroid treatment, diabetes, hypertension, cardiovascular disease, weight loss, hypoproteinemia, anemia, metabolic disorders, the distance of the anastomosis from the anal verge and the experience of the surgeon (2-5,16,29,39-45). Additionally, laparoscopic rectal transection in the lower rectum utilizes at least two linear staplers (in the present study, the median number of linear stapler firings in the two groups was 3) with a cutter, which may lead to an excessively long stapling line with an inadequate cutting angle, which may increase the incidence of AL $(1,10)$. Thereafter, protection of the anastomosis in LARRC was inevitable in certain high-risk patients.

To protect the anastomosis and avoid additional reversal surgery, the Department of Colorectal Surgery, First Affiliated Hospital,Zhejiang University, developed two surgical methods, VIB and SCCI. However, the VIB technique was not suitable for patients in whom the anastomosis was too far from the anal verge $(>7 \mathrm{~cm})$ or in whom the colon wall was too thick. Furthermore, the protected period in the VIB group could not be controlled, and so could not be prolonged artificially when the AL persisted. Nevertheless, SCCI is able to solve these problems and has been used in open procedures and hand-assisted laparoscopic surgery (24-26). The interrupted cyclic fixation step from the ileum to the peritoneum was completed through the abdominal incision, as settling of the stoma position in the right lower abdomen prevented completion of this step under the laparoscopic incision. Furthermore, this step was key to preventing abdominal infection following tube extraction and maintaining adhesion of the bowel and peritoneum to the tube. These issues prevented use of the SCCI method in LARRC. In the present study, the stoma position was transferred from the right lower abdomen to the puncture hole closely inferior to the umbilicus. Subsequently, the interrupted cyclic fixation step was able to be finished through the laparoscopic incision, as the distance from the incision to the cannula ileostomy was sufficiently decreased. Additionally, there was an adjustment to the surgical detail; a previous study indicated that a double row of concentric purse string sutures was required (24), whereas the patients in the present study accepted a single row of purse string sutures in the distal ileum. However, no suture-associated adverse events were detected in any cases. Therefore, the results of the present study suggest that a single row of purse string sutures is sufficient, which will decrease the duration of surgery by several min.

No statistical significance was evident in the majority of the parameters between the SCCI and ileostomy groups in LARRC; however, the total cost, length of postoperative stay and stoma period were significantly improved in the SCCI group $(\mathrm{P}<0.001)$, with reversal surgery in the ileostomy group as an underlying influencing factor. These results suggested that the SCCI procedure in LARRC obviates the requirement for reversal surgery, and exhibits safety comparable to the ileostomy group in the primary surgery. The results of the present study supported previous data from a large sample study in open and hand-assisted laparoscopic low anterior resection (24), in which it was revealed that the overall postoperative hospital stay $(\mathrm{P}<0.01)$ and cost $(\mathrm{P}<0.01)$ were increased in the Ileostomy group compared with the SCCI group.

As aforementioned, 1 patient in the SCCI group experienced AL at day 6 postoperatively, with the manifestation of a fever (38.5-38. $8^{\circ} \mathrm{C}$ for 2 days and $37.8-38.2^{\circ} \mathrm{C}$ for 3 days) and drainage of a small amount of muddy liquid (10-20 $\mathrm{ml}$ for 6 days). Due to the protection offered by SCCI, feces had not passed through the anastomosis, which may have contributed to the absence of serious peritonitis. Therefore, this patient was cured without requiring emergency surgery. Whether defunctioning stoma can prevent AL remains unknown, however, it decreases the incidence of sepsis and emergency surgery due to fecal diversion $(17,18,46,47)$. Furthermore, AL typically presents 2-17 days postoperatively (48), therefore the key stage during which fecal diversion must be maintained is 3-4 weeks postoperatively. In the present study, the median protected period was 22 days, during which the anastomosis was effectively protected. Additionally, the air bag filled with normal saline prevented downward intestinal content travel; although the ileum cavity was slowly expanded to relieve the block, more normal saline could be injected into the air bag 
to maintain the blocking of feces. To prolong the protected period, use of two separate single-row nails to block the ileum is currently under investigation. The two novel aforementioned methods may prolong the protected period significantly.

A total of 2 patients had stapled anastomotic stenosis in the ileostomy group; thus, an additional procedure to relieve the stenosis was required. These 2 patients were among the 3 patients who underwent neoadjuvant radio-chemotherapy preoperatively. However, no stenosis occurred in the SCCI group, although 3 patients received neoadjuvant radio-chemotherapy preoperatively. According to the National Comprehensive Cancer Network guidelines (49), patients with locally advanced cancer are suggested to undergo neoadjuvant radio-chemotherapy preoperatively. However, these patients exhibit an increased rate of anastomotic stenosis, which is associated with the period for the absence of feces passing through the anastomosis (50-54). For the majority of patients in the SCCI group in the present study, anal defecation recovered in less than a month, which may prevent stenosis and the requirement for additional surgery. Additionally, SCCI did not affect postoperative chemotherapy; chemotherapy was able to be administered prior to cannula stoma closure or even prior to cannula removal.

In conclusion, despite the small size of the treatment groups and the non-randomized nature of the present study, results demonstrated that in LARRC, the SCCI procedure appeared to be a safe, feasible diverting technique to protect the anastomosis. Compared with ileostomy, the SCCI procedure obviated the requirement for stoma reversal surgery, which resulted in a decreased postoperative hospital stay, hospitalization costs and stoma period.

\section{Acknowledgements}

The present study was supported by the Public Welfare Technology Research Project and the Science and Technology Department of Zhejiang, China (grant no. 2015C33208).

\section{References}

1. Targarona EM,Balague C,Pernas JC, Martinez C, Berindoague R, Gich I and Trias M: Can we predict immediate outcome after laparoscopic rectal surgery? Multivariate analysis of clinical, anatomic, and pathologic features after 3-dimensional reconstruction of the pelvic anatomy. Ann Surg 247: 642-649, 2008.

2. Branagan G and Finnis D; Wessex Colorectal Cancer Audit Working Group: Prognosis after anastomotic leakage in colorectal surgery. Dis Colon Rectum 48: 1021-1026, 2005.

3. Matthiessen P, Hallböök $\mathrm{O}$, Andersson $\mathrm{M}$, Rutegård $\mathrm{J}$ and Sjödahl R: Risk factors for anastomotic leakage after anterior resection of the rectum. Colorectal Dis 6: 462-469, 2004.

4. Park JS, Choi GS, Kim SH, Kim HR, Kim NK, Lee KY, Kang SB, Kim JY, Lee KY, Kim BC, et al: Multicenter analysis of risk factors for anastomotic leakage after laparoscopic rectal cancer excision: The Korean laparoscopic colorectal surgery study group. Ann Surg 257: 665-671, 2013.

5. Yeh CY, Changchien CR, Wang JY, Chen JS, Chen HH, Chiang JM and Tang R: Pelvic drainage and other risk factors for leakage after elective anterior resection in rectal cancer patients: A prospective study of 978 patients. Ann Surg 241: 9-13, 2005.

6. Anthuber M, Fuerst A, Elser F, Berger R and Jauch KW: Outcome of laparoscopic surgery for rectal cancer in 101 patients. Dis Colon Rectum 46: 1047-1053, 2003.

7. Feliciotti F, Guerrieri M, Paganini AM, De Sanctis A, Campagnacci R, Perretta S, D'Ambrosio G and Lezoche E: Long-term results of laparoscopic versus open resections for rectal cancer for 124 unselected patients. Surg Endosc 17: 1530-1535, 2003.
8. Park JS, Choi GS, Jun SH, Hasegawa S and Sakai Y: Laparoscopic versus open intersphincteric resection and coloanal anastomosis for low rectal cancer: Intermediate-term oncologic outcomes. Ann Surg 254: 941-946, 2011

9. Zhou ZG, Hu M, Li Y, Lei WZ, Yu YY, Cheng Z, Li L, Shu Y and Wang TC: Laparoscopic versus open total mesorectal excision with anal sphincter preservation for low rectal cancer. Surg Endosc 18: 1211-1215, 2004.

10. Akiyoshi T, Ueno M, Fukunaga Y, Nagayama S, Fujimoto Y, Konishi $\mathrm{T}$, Kuroyanagi $\mathrm{H}$ and Yamaguchi $\mathrm{T}$ : Incidence of and risk factors for anastomotic leakage after laparoscopic anterior resection with intracorporeal rectal transection and double-stapling technique anastomosis for rectal cancer. Am J Surg 202: 259-264, 2011.

11. Wang YW, Huang LY, Song CL, Zhuo CH, Shi DB, Cai GX, $\mathrm{Xu}$ Y, Cai SJ and Li XX: Laparoscopic vs open abdominoperineal resection in the multimodality management of low rectal cancers. World J Gastroenterol 21: 10174-10183, 2015.

12. Liu Z, Kang L, Huang M, Luo Y, Wang L, Lan P, Cui J and Wang J: Open surgery against laparoscopic surgery for mid-rectal or low-rectal cancer of male patients: better postoperative genital function of laparoscopic surgery. Surg Laparosc Endosc Percutan Tech 25: 444-448, 2015.

13. Li S, Jiang F, Tu J and Zheng X: Long-term oncologic outcomes of laparoscopic versus open surgery for middle and lower rectal cancer. PLoS One 10: e0135884, 2015.

14. Vargas GM, Sieloff EP, Parmar AD, Tamirisa NP, Mehta HB and Riall TS: Laparoscopy decreases complications for obese patients undergoing elective rectal surgery. Surg Endosc 30: 1826-1832, 2016.

15. Bell SW, Walker KG, Rickard MJ, Sinclair G, Dent OF, Chapuis PH and Bokey EL: Anastomotic leakage after curative anterior resection results in a higher prevalence of local recurrence. Br J Surg 90: 1261-1266, 2003.

16. Jung SH, Yu CS, Choi PW, Kim DD, Park IJ, Kim HC and Kim JC: Risk factors and oncologic impact of anastomotic leakage after rectal cancer surgery. Dis Colon Rectum 51: 902-908, 2008.

17. Matthiessen P, Hallbook O, Rutegard J, Simert G and Sjödahl R: Defunctioning stoma reduces symptomatic anastomotic leakage after low anterior resection of the rectum for cancer: A randomized multicenter trial. Ann Surg 246: 207-214, 2007.

18. Huser N, Michalski CW, Erkan M, Schuster T, Rosenberg R, Kleeff $J$ and Friess H: Systematic review and meta-analysis of the role of defunctioning stoma in low rectal cancer surgery. Ann Surg 248: 52-60, 2008.

19. Shiomi A, Ito M, Saito N, Ohue M, Hirai T, Kubo Y and Moriya Y: Diverting stoma in rectal cancer surgery. A retrospective study of 329 patients from Japanese cancer centers. Int J Colorectal Dis 26: 79-87, 2011.

20. Yoo SB, Jeong SY, Lim SB, Park JW, Choi HS and Oh JH: Left-sided ileostomy at specimen extraction site in laparoscopic-assisted low anterior resection for rectal cancer. J Laparoendosc Adv Surg Tech A 23: 22-25, 2013.

21. Chang D, Zhang Y, Dang C, Zhu K, Li K, Chen D and Chen W: Prevention of anastomotic leakage after low anterior resection in rectal cancers. Hepatogastroenterology 57: 477-481, 2010.

22. Ye F, Wang D, Xu X, Liu F and Lin J: Use of intracolonic bypass secured by a biodegradable anastomotic ring to protect the low rectal anastomosis. Dis Colon Rectum 51: 109-115, 2008.

23. YeF, Chen D, Wang D, Lin J and Zheng S: Use of Valtrac ${ }^{\mathrm{TM}}$-secured intracolonic bypass in laparoscopic rectal cancer resection. Medicine (Baltimore) 93: e224, 2014.

24. Hua H, Xu J, Chen W, Zhou X, Wang J, Sheng Q and Lin J: Defunctioning cannula ileostomy after lower anterior resection of rectal cancer. Dis Colon Rectum 57: 1267-1274, 2014.

25. Wang J, Ke B, Lin J, Xu J and Chen W: Application of a spontaneously closed protective stoma in an ileal pouch-anal anastomosis: A preliminary study. Int J Clin Exp Med 8: $1281-1285,2015$.

26. Xu JZ, Wang J, Hua H, Lin C Liu F, Li Y, Chen W: Spontaneously closed protective stoma: A preliminary report of exploratory study. Chin J Practical Surg 32: 1040-1042, 2012.

27. Edge SB and Compton CC: The American Joint Committee on Cancer: The 7th edition of the AJCC cancer staging manual and the future of TNM. Ann Surg Oncol 17: 1471-1474, 2010.

28. Reyngold M, Niland J, ter Veer A, Milne D, Bekaii-Saab T, Cohen SJ, Lai L, Schrag D, Skibber JM, Small W Jr, et al: Neoadjuvant radiotherapy use in locally advanced rectal cancer at NCCN member institutions. J Natl Compr Canc Netw 12: 235-243, 2014. 
29. Peeters KC, Tollenaar RA, Marijnen CA, Klein Kranenbarg E, Steup WH, Wiggers T, Rutten HJ and van de Velde CJ; Dutch Colorectal Cancer Group: Risk factors for anastomotic failure after total mesorectal excision of rectal cancer. Br J Surg 92: 211-216, 2005.

30. Rudinskaite $\mathrm{G}$ and Pavalkis D: Coloanal anastomosis in rectal cancer surgery. Medicina (Kaunas) 38: 624-630, 2002.

31. Karanjia ND, Corder AP, Bearn P and Heald RJ: Leakage from stapled low anastomosis after total mesorectal excision for carcinoma of the rectum. Br J Surg 81: 1224-1226, 1994.

32. Dehni N, Schlegel RD, Cunningham C, Guiguet M, Tiret E and Parc R: Influence of a defunctioning stoma on leakage rates after low colorectal anastomosis and colonic J pouch-anal anastomosis. Br J Surg 85: 1114-1117, 1998.

33. Ashburn JH, Stocchi L, Kiran RP, Dietz DW and Remzi FH: Consequences of anastomotic leak after restorative proctectomy for cancer: Effect on long-term function and quality of life. Dis Colon Rectum 56: 275-280, 2013.

34. Law WL, Choi HK, Lee YM, Ho JW and Seto CL: Anastomotic leakage is associated with poor long-term outcome in patients after curative colorectal resection for malignancy. J Gastrointest Surg 11: 8-15, 2007.

35. Laxamana A, Solomon MJ, Cohen Z, Feinberg SM, Stern HS and McLeod RS: Long-term results of anterior resection using the double-stapling technique. Dis Colon Rectum 38: 1246-1250, 1995.

36. Mirnezami A, Mirnezami R, Chandrakumaran K, Sasapu K, Sagar P and Finan P: Increased local recurrence and reduced survival from colorectal cancer following anastomotic leak: Systematic review and meta-analysis. Ann Surg 253: 890-899, 2011.

37. Rullier E, Laurent C, Garrelon JL, Michel P, Saric J and Parneix M: Risk factors for anastomotic leakage after resection of rectal cancer. Br J Surg 85: 355-358, 1998.

38. Scott N, Jackson P, al-Jaberi T, Dixon MF, Quirke P and Finan PJ: Total mesorectal excision and local recurrence: A study of tumour spread in the mesorectum distal to rectal cancer. Br J Surg 82: 1031-1033, 1995.

39. Buchs NC, Gervaz P, Secic M, Bucher P, Mugnier-Konrad B and Morel P: Incidence, consequences and risk factors for anastomotic dehiscence after colorectal surgery: A prospective monocentric study. Int J Colorectal Dis 23: 265-270, 2008.

40. Buie WD, MacLean AR, Attard JA, Brasher PM and Chan AK: Neoadjuvant chemoradiation increases the risk of pelvic sepsis after radical excision of rectal cancer. Dis Colon Rectum 48 $1868-1874,2005$.

41. Choi HK, Law WL and Ho JW: Leakage after resection and intraperitoneal anastomosis for colorectal malignancy: Analysis of risk factors. Dis Colon Rectum 49: 1719-1725, 2006.

42. Leichtle SW, Mouawad NJ, Welch KB, Lampman RM and Cleary RK: Risk factors for anastomotic leakage after colectomy. Dis Colon Rectum 55: 569-575, 2012.
43. Lipska MA, Bissett IP, Parry BR and Merrie AE: Anastomotic leakage after lower gastrointestinal anastomosis: Men are at a higher risk. ANZ J Surg 76: 579-585, 2006.

44. Martel G, Al-Suhaibani Y, Moloo H, Haggar F, Friedlich M, Mamazza J, Poulin EC, Stern H and Boushey RP: Neoadjuvant therapy and anastomotic leak after tumor-specific mesorectal excision for rectal cancer. Dis Colon Rectum 51: 1195-1201, 2008.

45. Zaharie F, Mocan L, Tomus C, Mocan T, Zaharie R, Bartos D, Bartoş A, Vlad L and Iancu C: Risk factors for anastomotic leakage following colorectal resection for cancer. Chirurgia (Bucur) 107: 27-32, 2012.

46. Smith JD, Paty PB, Guillem JG, Temple LK, Weiser MR and Nash GM: Anastomotic leak is not associated with oncologic outcome in patients undergoing low anterior resection for rectal cancer. Ann Surg 256: 1034-1038, 2012.

47. Lin JK, Yueh TC, Chang SC, Lin CC, Lan YT, Wang HS, Yang SH, Jiang JK, Chen WS and Lin TC: The influence of fecal diversion and anastomotic leakage on survival after resection of rectal cancer. J Gastrointest Surg 15: 2251-2261, 2011.

48. Tai JD, Liu YS and Wang GY: Risk factors and the management of anastomotic leakage after anus-preserving operation for rectal cancer. Zhonghua Wei Chang Wai Ke Za Zhi 10: 153-156, 2007 (In Chinese)

49. Network. NCC: NCCN Clinical Practice Guidelines in Oncology: Rectal cancer. Version I. In: Washington, National Comprehensive Cancer Network, 2015.

50. Widder J, Herbst F, Dobrowsky W, Schmid R, Pokrajac B, Jech B, Chiari C, Stift A, Maier A, Karner-Hanusch J, et al: Preoperative short-term radiation therapy (25 Gy, 2.5 Gy twice daily) for primary resectable rectal cancer (phase II). Br J Cancer 92: 1209-1214, 2005

51. Luna-Pérez P, Rodríguez-Ramírez S, Rodriguez-Coria DF, Fernández A, Labastida S, Silva A and López MJ: Preoperative chemoradiation therapy and anal sphincter preservation with locally advanced rectal adenocarcinoma. World J Surg 25: 1006-1011, 2001.

52. Luna-Pérez P, Rodríguez-Ramírez S, Hernández-Pacheco F, Gutiérrez De La Barrera M, Fernández R and Labastida S: Anal sphincter preservation in locally advanced low rectal adenocarcinoma after preoperative chemoradiation therapy and coloanal anastomosis. J Surg Oncol 82: 3-9, 2003.

53. Chan A, Wong A, Langevin J and Khoo R: Preoperative concurrent 5-fluorouracil infusion, mitomycin $\mathrm{C}$ and pelvic radiation therapy in tethered and fixed rectal carcinoma. Int J Radiat Oncol Biol Phys 25: 791-799, 1993.

54. Brigand C, Rohr S and Meyer C: Colorectal stapled anastomosis: Results after anterior resection of the rectum for cancer. Ann Chir 129: 427-432, 2004. 